\title{
RETROSPECTIVE ANALYSIS OF BONE METABOLISM IN PATIENTS WAITING FOR SIMULTANEOUS PANCREAS KIDNEY TRANSPLANTATION
}

\author{
S. Kratochvílová, M. Zahradnická, J. Brunová \\ Diabetes Centre, Institute for Clinical and Experimental Medicine \\ Prague, Czech Republic
}

\section{INTRODUCTION:}

Osteoporosis is a typical long-term complication after solid organ

transplantation. Patients after simultaneous pancreas kidney transplantation (SPK) are at a very high risk due to preceding renal osteopathy and diabetic status and the risk of fracture is extraordinary elevated.

Pathogenesis:

The negative impact of type 1 diabetes (T1DM) is mediated through deficient insulin anabolic effect on osteoblasts, toxic impact of hyperglyceamia on osteoblasts, AGE's cummulation in bone matrix, neuropathy, microangiopathy and calcium and magnesium loss due to polyuria. Moreover if diabetic nefropathy deteriorates into chronic kidney disease (CKD), bone impairment due to secondary hyperparathyreosis, hypocalcemia and vitamine $\mathrm{D}$ deficiency develops since CKD 2. Additional negative factors (malnutrition,

immobilization, hypogonadism, medication...) may contribute to the bone loss.

RESULTS:

Characteristics of the study group

\begin{tabular}{|c|c|c|c|c|}
\hline & Total $(n=111)$ & Men $(n=68)$ & Women $(n=43)$ & Significance \\
\hline Age (years) & $40,71 \pm 10,44$ & $42,93 \pm 10,47$ & $37,21 \pm 9,49$ & $P=0,004$ \\
\hline DM duration (years) & $24,69 \pm 7,98$ & $24,19 \pm 7,73$ & $25,49 \pm 8,37$ & NS \\
\hline BMI (kg/m2) & $24,65 \pm 3,48$ & $25,22 \pm 3,36$ & $23,75 \pm 3,51$ & $P=0,03$ \\
\hline $\mathrm{HbA1c}(\mathrm{mmol} / \mathrm{mol})$ & $73,07 \pm 17,15$ & $73,02 \pm 14,82$ & $73,05 \pm 20,67$ & NS \\
\hline GF (ml/s) & $0,24 \pm 0,12$ & $0,26 \pm 0,13$ & $0,20 \pm 0,1$ & $P=0,014$ \\
\hline CKD 4 (GF > 0,25ml/s) & 44 & 33 & 11 & \\
\hline CKD 5 (GF < 0,25ml/s) & 27 & 9 & 18 & \\
\hline CKD 5D (31 HD, 9 PD) & 40 & 26 & 14 & \\
\hline $\mathrm{Ca}(\mathrm{mmol} / \mathrm{l})$ & $2,24 \pm 0,27$ & $2,28 \pm 0,31$ & $2,19 \pm 0,17$ & NS $(p=0,09)$ \\
\hline$P(\mathrm{mmol} / \mathrm{l})$ & $1,67 \pm 0,36$ & $1,62 \pm 0,3$ & $1,77 \pm 0,43$ & $P=0,03$ \\
\hline iPTH (pmol/l) & $19,05 \pm 13,32$ & $18,35 \pm 12,86$ & $20,2 \pm 14,13$ & NS \\
\hline 25-OH vitamin D (ug/l) (n=84) & $15,49 \pm 7,67$ & $15,59 \pm 6,7$ & $15,31 \pm 9,3$ & NS \\
\hline $1,25-\mathrm{OH}$ vitamin $\mathrm{D}(\mathrm{ug} / \mathrm{l})(\mathrm{n}=83)$ & $19,3 \pm 14,1$ & $19,38 \pm 13,42$ & $19,12 \pm 15,74$ & NS \\
\hline
\end{tabular}

\section{OBJECTIVE:}

To determine the best preventive strategy we analysed the bone metabolism at the point of the pretransplant examination.

\section{DESIGN AND METHODS:}

In years 2011-2014 the number of 112 patients with type 1 diabetes entered the waiting list for the SPK for the first time. We retrospectively analyzed biochemical results $(\mathrm{Ca}, \mathrm{P}, \mathrm{iPTH}$, vitamin $\mathrm{D} 25-\mathrm{OH}, 1,25-\mathrm{OH})$ and the bone densitometry (lumbal spine, proximal femur, distal radius $T$ and $Z$ score; Lunar Prodigy) from their pretransplant investigation (2010-2014). The densitometry was not available in 1 patient, the final analysis comprised 111 patients.

STATISTICAL ANALYSIS: Values are reported as means \pm SD. The unpaired T test was used to compare the study subgroups. The Pearson correlation coefficient was performed to evaluate the associations between anthropometric and osteological parameters. $P$ value $\leq 0,05$ was considered statistically significant. GraphPad Prism 5 statistical sofrware was used for the data analysis.

\section{Relationship between PTH and GF}

GF $(\mathrm{ml} / \mathrm{s})$
$24 \%$ of patients had $\mathbf{2 5 - O H}$ vitamin D deficiency (<10ug/l), only $2 \%$ had normal level $(>30 \mathrm{ug} / \mathrm{l})$.

Bone mineral density

\begin{tabular}{|l|l|c|c|c|l|}
\hline & & $\begin{array}{c}\text { Total } \\
(n=111)\end{array}$ & $\begin{array}{c}\text { Men } \\
(\mathrm{n}=68)\end{array}$ & $\begin{array}{c}\text { Women } \\
(\mathrm{n}=43)\end{array}$ & Significance \\
\hline \multirow{2}{*}{ LUMBAL SPINE } & $\mathrm{T}$ & $-0,94 \pm 1,38$ & $-1,19 \pm 1,23$ & $-0,54 \pm 1,46$ & $\mathrm{P}=0,015$ \\
\cline { 2 - 6 } & $\mathrm{Z}$ & $-0,83 \pm 1,42$ & $-1,09 \pm 1,29$ & $-0,42 \pm 1,54$ & $\mathrm{P}=0,015$ \\
\hline $\begin{array}{l}\text { PROXIMAL } \\
\text { FEMUR }\end{array}$ & $\mathrm{T}$ & $-1,39 \pm 1,12$ & $-1,44 \pm 1,00$ & $-1,31 \pm 1,27$ & $\mathrm{NS}$ \\
\cline { 2 - 6 } & $\mathrm{Z}$ & $-1,16 \pm 1,14$ & $-1,19 \pm 1,03$ & $-1,10 \pm 1,31$ & $\mathrm{NS}$ \\
\hline $\begin{array}{l}\text { DISTAL RADIUS } \\
(\mathrm{n}=95)\end{array}$ & $\mathrm{T}$ & $-0,89 \pm 1,01$ & $-0,87 \pm 1,06$ & $-0,88 \pm 0,98$ & NS \\
\cline { 2 - 6 } & $\mathrm{Z}$ & $-0,80 \pm 1,05$ & $-0,82 \pm 1,11$ & $-0,78 \pm 1,00$ & NS \\
\hline
\end{tabular}

Men have significantly lower BMD in lumbal spine than women

$\mathrm{T}$ - and Z- score of the proximal femur is significantly lower than that of the lumbar spine or distal radius.

Bone mineral density in subgroups

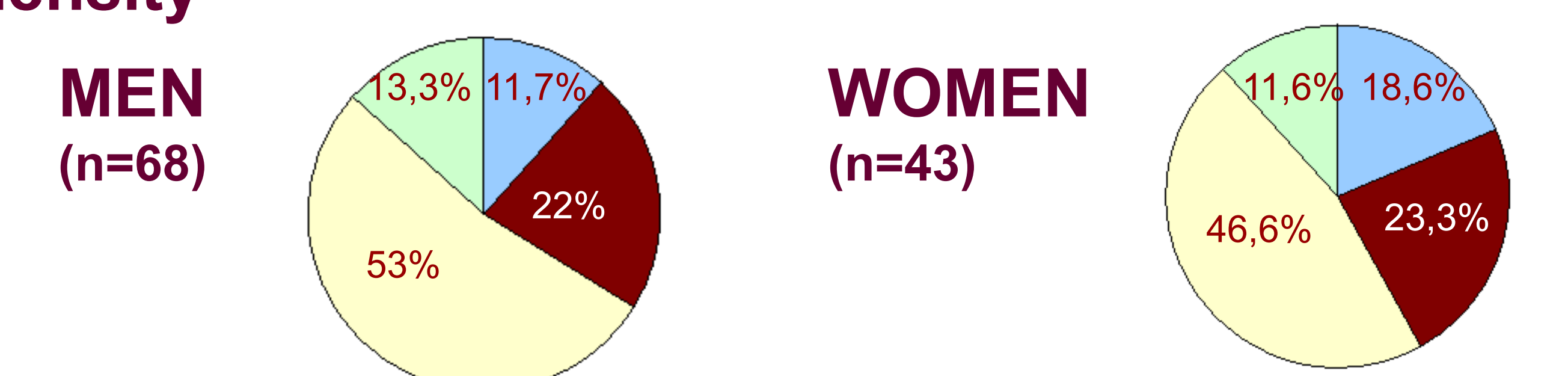

Similar prevalence of osteoporosis

between men and women

Bone mineral density (the whole group)

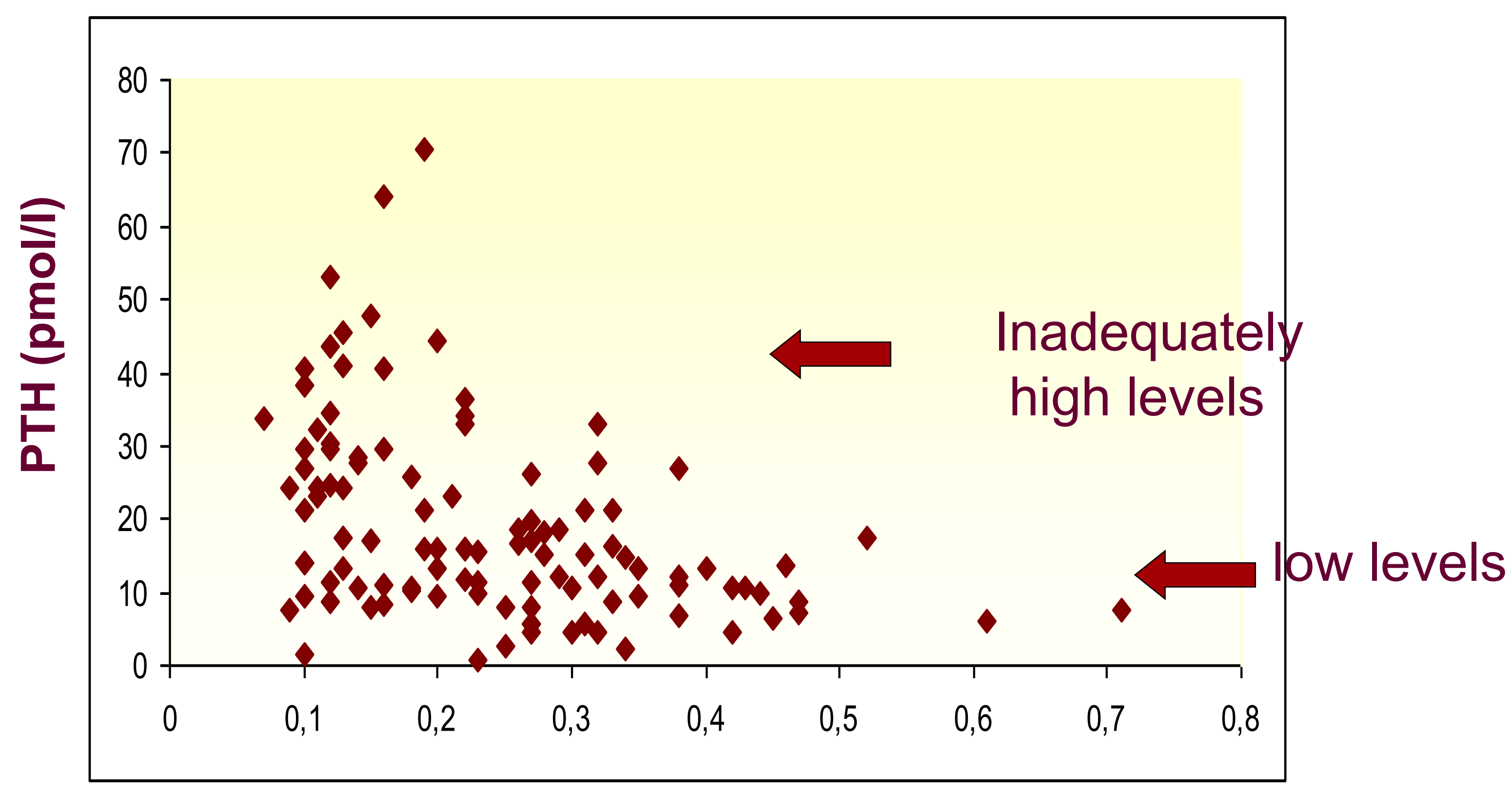

T skóre

$<2,5$ OSTEOPOROSIS $<1,0$ OSTEOPENIA $<0,5$ LOW NORMAL BMD $\geq 0,5$ NORMAL BMD

$50,5 \%$ $22,5 \%$

High prevalence of osteoporosis and osteopenia in young patients.
Correlations among BMD and anthropometric parameters

\begin{tabular}{|c|c|c|c|c|c|}
\hline & & BMI (kg/m2) & Age (years) & $\begin{array}{l}\text { Duration of T1DM } \\
\text { (years) }\end{array}$ & $\begin{array}{l}\text { The age of T1DM } \\
\text { diagnosis (years) }\end{array}$ \\
\hline \multirow{2}{*}{$\begin{array}{l}\text { THE WHOLE } \\
\text { STUDY GROUP } \\
(n=111)\end{array}$} & LP (g/cm2) & $r=0,31(p<0,001)$ & $r=0,22(p=0,02)$ & $r=0,18(p=0,056)$ & $r=0,08$ (NS) \\
\hline & $\operatorname{PF}(\mathrm{g} / \mathrm{cm} 2)$ & $r=0,46(p<0,001)$ & $r=0,24(p=0,01)$ & $\mathrm{r}=0,1$ (NS) & $\mathrm{r}=0,16$ (NS) \\
\hline \multirow{2}{*}{$\begin{array}{c}\text { MEN } \\
(n=68)\end{array}$} & LP (g/cm2) & $r=0,24(p=0,054)$ & $r=0,16$ (NS) & $r=0,16$ (NS) & $r=0,21$ (NS) \\
\hline & $\operatorname{PF}(\mathrm{g} / \mathrm{cm} 2)$ & $r=0,36(p=0,002)$ & $\mathrm{r}=0,2$ (NS) & $\mathrm{r}=0,2$ (NS) & $r=0,23(p=0,058)$ \\
\hline \multirow{2}{*}{$\begin{array}{l}\text { WOMEN } \\
(n=43)\end{array}$} & LP (g/cm2) & $r=0,48(p<0,001)$ & $\mathrm{r}=0,43(\mathrm{p}=0,004)$ & $r=0,46(p=0,002)$ & $r=-0,06$ (NS) \\
\hline & $\mathrm{PF}(\mathrm{g} / \mathrm{cm} 2)$ & $r=0,56(p<0,001)$ & $r=0,23$ (NS) & $r=0,32(p=0,04)$ & $r=-0,15$ (NS) \\
\hline
\end{tabular}

BMD and the age of T1DM diagnosis Z score

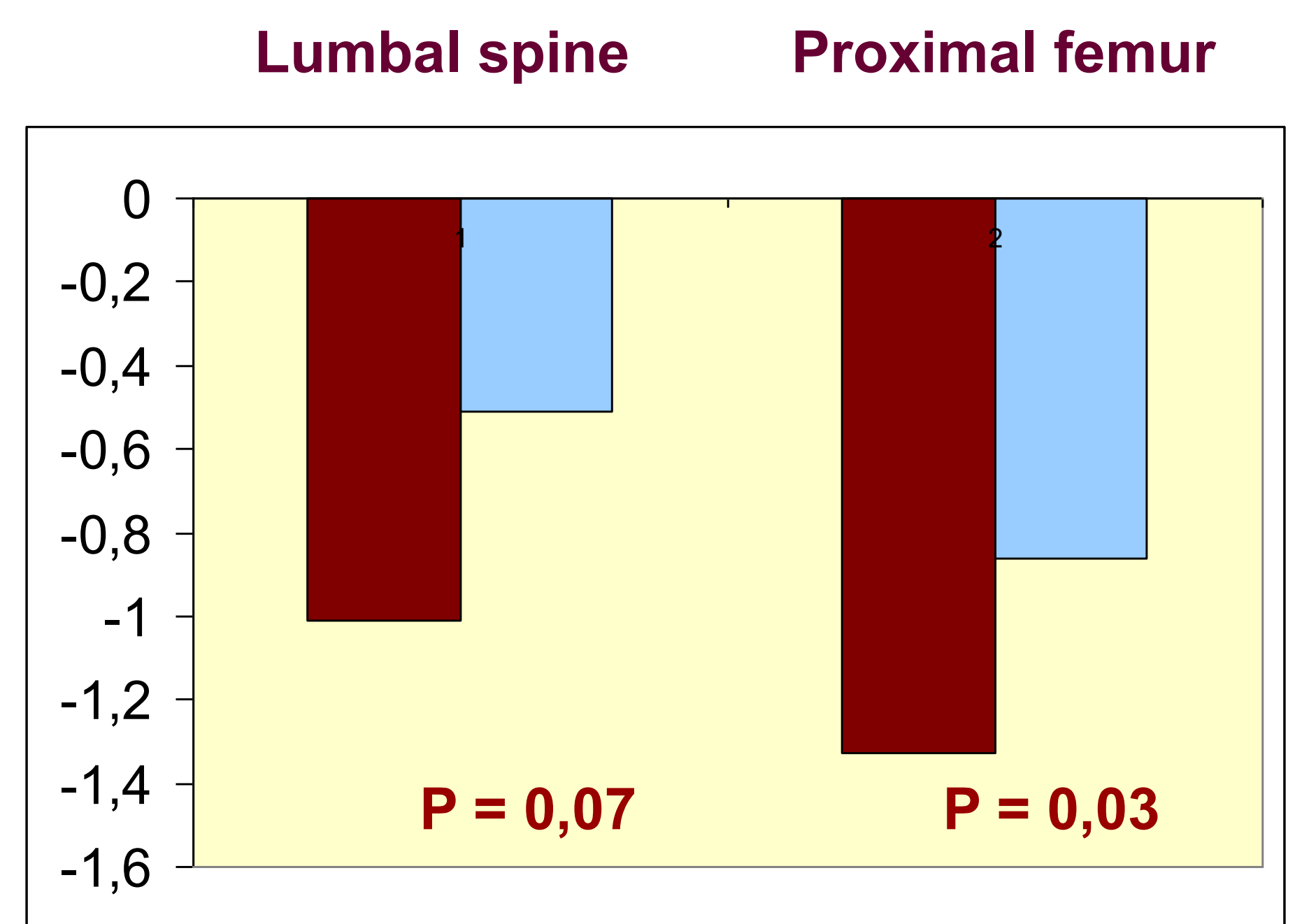

Surprisingly positive correlation between BMD and age and BMD and the duration of diabetes.

CONCLUSIONS: Patients with type 1 diabetes in CKD 3-5 suffer from serious bone mineral density impairment despite their young age. On contrast to population data the incidence of low bone density is the same among men and women. Proximal femur is the most affected area. Patients with type 1 diabetes since early childhood are at a very high risk of having low BMD.

Bone metabolism should be monitored since early stages of diabetic nephropathy and adequate preventive measures (sufficient vitamine $D$ intake in the first place) should be introduced.

Supported by the Ministry of Health of the Czech Republic (MZO 00023001)

Age under $15 y e a r s(n=69)$ later $(n=42)$

T1DM diagnosis in childhood and early adolescence negatively affects the peak bone mass with the impact for the rest of the life. 